\title{
Papillary Carcinoma Arising From Infrahyoid Ectopic Thyroid Tissue with Hemi-agenesis of Thyroid Gland and Follicular Adenoma with Hürthle Cell Changes in Existing Thyroid Lobe: A Rare Case Report
}

\author{
Md. Sunny Anam Chowdhury and Md. Abdul Awal \\ Institute of Nuclear Medicine and Allied Sciences, Bogra
}

Correspondence Address: Md. Sunny Anam Chowdhury, Senior Medical Officer, Institute of Nuclear Medicine and Allied sciences, Bogra, GPO Box \# 61, Mohammad Ali Hospital Campus, E-mail: drsunny43@gmail.com

\begin{abstract}
Ectopic thyroid tissue is a rare developmental abnormality. An ectopic thyroid tissue can be subject to various pathological processes as normal thyroid tissue including tumorigenesis. This reported case is an extremely rare case of papillary thyroid carcinoma arising from infrahyoid ectopic thyroid tissue with hemiagenesis (left lobe) of thyroid gland and presence of follicular adenoma with Hürthle cell changes in the normal positioned enlarged right thyroid lobe.
\end{abstract}

Key words: Ectopic thyroid cancer, infrahyoid ectopic thyroid.

\section{INTRODUCTION}

Thyroid ectopia is the most frequent form of thyroid dysgenesis, accounting 48-61\% of the cases. Ectopic thyroid tissue can be found anywhere along its embryologic path - from foramen caecum to normal cervical position between second and fourth tracheal cartilage along anterior neck known as thyroglossal duct $(1,2)$. The incidence of ectopic thyroid has been reported about 1 per 100000-300000 people (1). Ectopic thyroid tissue is most frequently reported in the lingual, thyroglossal and laryngotracheal sites (2). As in normal thyroid tissue various pathological conditions such as inflammation, hyperplasia and tumor formation may be found in ectopic thyroid tissue (3). The probability of carcinoma in ectopic thyroid tissue is less than $1 \%(3,4)$. Most common tumors of ectopic thyroid tissue have been reported as papillary carcinoma $(1,5)$. However, follicular, mixed follicular, papillary Hürthle cell and medullary carcinoma have also been reported (5-7). We report a rare case of papillary carcinoma of thyroid in ectopic thyroid tissue at infrahyoid position of anterior neck slightly left to midline with absence of left lobe of thyroid gland (hemiagenesis) and follicular adenoma with Hürthle cell in normal positioned mildly enlarged right thyroid lobe.

\section{CASE REPORT}

A 26 years old female patient came to Institute of Nuclear Medicine and Allied Sciences, Bogra presented with a gradually increasing anterior neck swelling above the level of thyroid gland and slightly to the left side for 7 months. Her medical history was unremarkable. Clinically, she was non-anaemic, with normal body temperature, pulse rate of about 78 beats/min and normotensive. No clinical feature of thyroid dysfunction was noted. Physical examination revealed a firm, non-tender mass in upper anterior neck above the level of thyroid gland and slightly left to the midline. Right lobe of thyroid gland was also palpable. No palpable lymphnode was found. Her free T3, free T4 and TSH level were found within normal ranges- $5.8 \mathrm{pmol} / \mathrm{L}$ (normal range: 2.8-9.5 pmol/L), $15.7 \mathrm{pmol} / \mathrm{L}$ (normal range: 9.5$25.5 \mathrm{pmol} / \mathrm{L}$ ) and $4.5 \mathrm{mIU} / \mathrm{L}$ (normal range: $0.3-5.0$ $\mathrm{mIU} / \mathrm{L})$ respectively.

On high resolution ultrasonographic scan, left lobe of thyroid gland was non-visualized. Right lobe was 
mildly enlarged with two closely adherent solid nodules measuring $2.4 \times 2.2 \mathrm{~cm}$ and $2.1 \times 1.8 \mathrm{~cm}$ in its lower part (Figure 1).

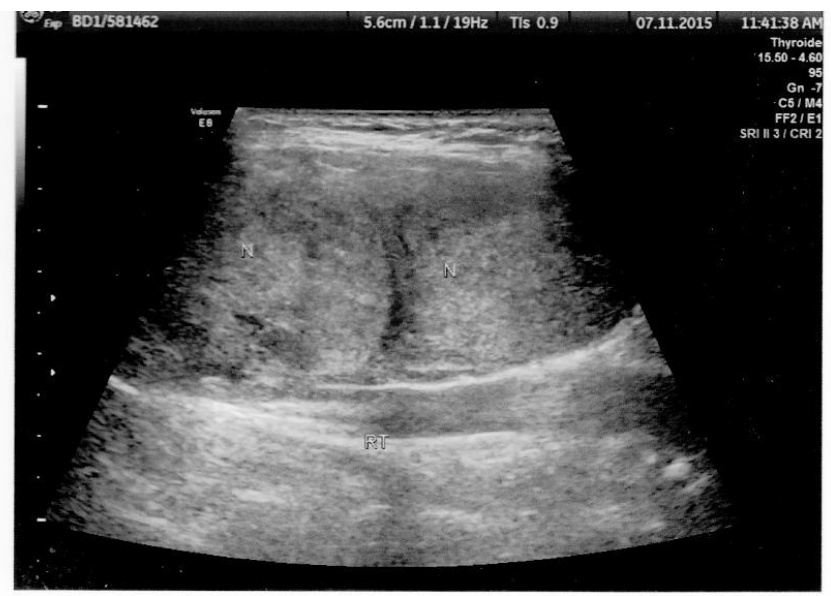

Figure 1: Solid nodules in lower part of right thyroid lobe

There was also an irregular outlined extra-thyroid solid mass of $26 \times 18 \mathrm{~mm}$, containing a $12 \times 9 \mathrm{~mm}$ irregular hypoechoic solid area with microcalcification, seen above the left thyroid bed and separated from the thyroid gland (Figure 2).

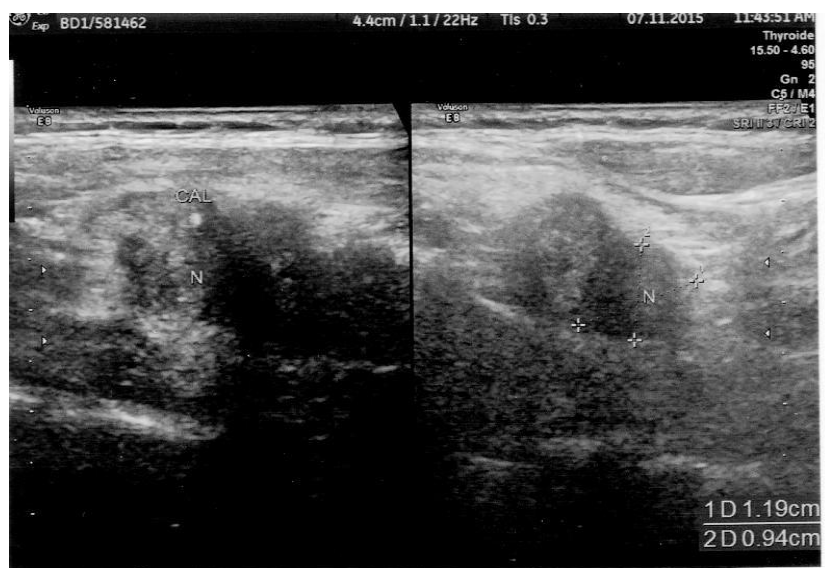

Figure 2: Ectopic thyroid tissue with solid hypoechoic nodule and microcalcification.

This mass was most-likely ectopic thyroid tissue. Radio-isotope (99mTc) thyroid scan shows enlarged right lobe of thyroid gland with two decreased areas of radiotracer accumulation at lower part of right lobe area indicating cold nodules in that part. No radiotracer accumulation was noted at the left lobe area. However, a small irregular shaped low tracer accumulation was noted above the level of thyroid bed at sonographically corresponding extra-thyroid solid mass indicating ectopic thyroid tissue with cold nodule within it (Figure 3).

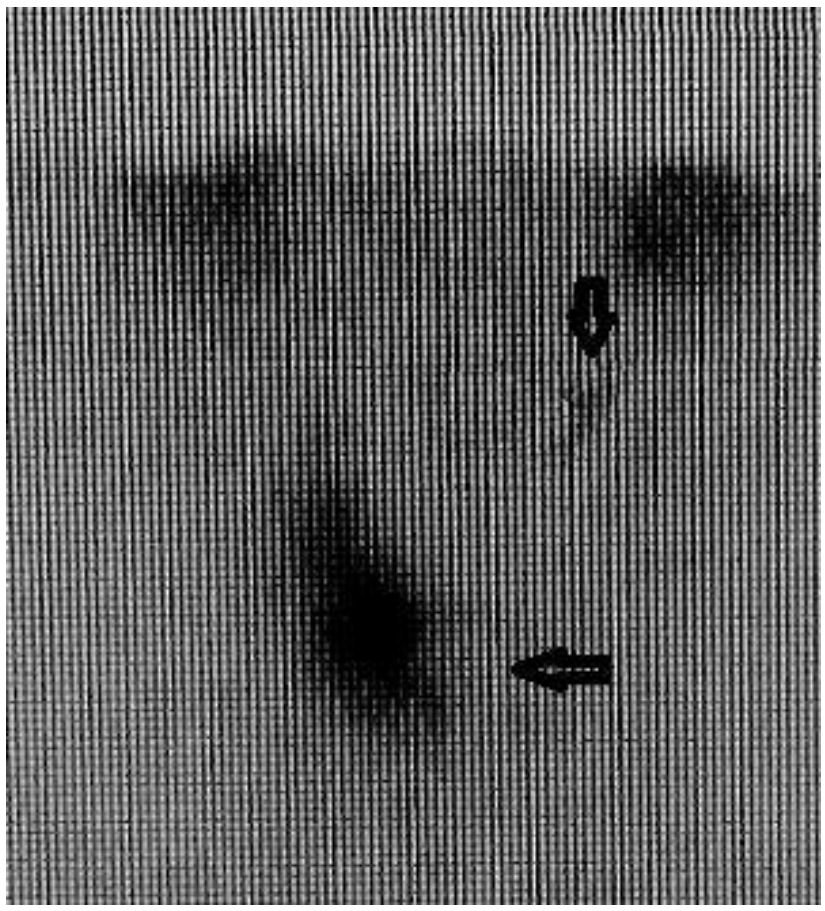

Figure 3: Thyroid scan showing cold nodules in enlarged right lobe (left arrow) and ectopic thyroid tissue (down arrow).

Then the patient was recommended for Fine Needle Aspiration Cytology (FNAC) of nodule of right lobe and extra-thyroid solid mass. FNAC report of extrathyroid mass was papillary carcinoma of thyroid gland. FNAC of right lobe shows colloid goiter. A CT scan showed a solid mass located in upper anterior neck below the level of hyoid bone and slightly left side with non-visualized left thyroid lobe and enlarged right lobe containing few solid nodules.

A surgery was performed under general anesthesia with excision of extrathyroid mass and total thyroidectomy. Histopathology of the extra-thyroid mass revealed papillary carcinoma of thyroid with degenerative changes and calcification. The tumor was limited with intact capsule. Tissue from right lobe showed follicular adenoma with Hürthle cell changes. The post-operative period was uneventful 
and the patient was referred for radioiodine ablation. Radioiodine (131I) therapy was given at a dose of 100 $\mathrm{mCi}$ on 43rd post-operative day. Then levothyroxine replacement therapy (at suppressive dose of 2.6 $\mathrm{mcg} / \mathrm{kg} /$ day) was started. Three months after therapy the patient was followed-up. She was clinically asymptomatic. Her serum free T4 level was 23.6 $\mathrm{pmol} / \mathrm{L}$, serum TSH level was $0.23 \mathrm{mIU} / \mathrm{L}$ and high resolution ultrasonography of neck shows no residual thyroid tissue in thyroid bed and at the level of the ectopic thyroid malignant tumor. Since post-therapy whole body iodine scan showed no evidence of metastasis, regular follow-up was advised.

\section{DISCUSSION}

Thyroid gland is the first endocrine gland that develops on approximately 24th day of gestation from pharyngeal endodermal diverticulum and descends from its origin at the foramen cecum along a pathway called thyroglossal duct and reaches to its normal anatomical position at anterior neck by 7th week of gestation $(1,8)$. An ectopic thyroid tissue may be defined as the presence of thyroid parenchyma at any location other than normal position, between the second and fourth tracheal cartilage. Failure of migration of medial anlage of thyroid or ultimobranchial bodies and incomplete obliteration of its vertical tract may result 'incomplete descent' and development of ectopic thyroid (9). Lingual thyroid is reported as the most common (about 90\%) types of ectopic thyroid. Other sites of ectopic thyroid tissue are suprahyoid, infrahyoid, lateral aberrant thyroid, substernal, struma ovary, larynx, trachea, oesophagus, pericardium, diaphragm and branchial cyst. Besides these in rare cases, ectopic thyroid tissue could be found in parathyroid, cervical lymphnodes, submandibular gland, duodenal mesentery, ascending aorta, heart, thymus, duodenum, gallbladder, stomach bed, pancreas, porta hepatis, fallopian tube, uterus and vagina (1). Prevalence of ectopic thyroid is about 1 per 100000-300000 people. Ectopic thyroid is more common in female with a Female-Male ratio of 1.25:1 $(1,8)$. In this case the female patient had normally positioned right thyroid lobe, but absent of the left thyroid lobe (hemiagenesis of thyroid gland). However, an area of ectopic thyroid tissue was found along the pathway of descend just below the level of hyoid bone and slightly left to the median plane. Ultrasonography and CT scan confirmed the extrathyroid mass, mildly enlarged right thyroid lobe containing nodules and absence of left lobe in left thyroid bed. Radioisotope scan showed presence of radiotracer in the extra-thyroid mass and confirmed ectopic thyroid tissue. Areas of decreased tracer accumulation in the right lobe and the ectopic thyroid tissue indicated cold nodules.

Ectopic thyroid tissue may be affected by similar pathological conditions as normal eutopic thyroid tissue as inflammation, hyperplasia and tumor formation (3). Primary malignant tumors arising from ectopic thyroid tissue are rare (less than 1\%). Only a few cases have been reported thyroid carcinoma to arise from lingual thyroid, thyroglossal duct cyst, lateral aberrant thyroid, median aberrant thyroid, mediastinal and struma ovarii $(1,10)$. Most tumors from ectopic thyroid tissue are papillary carcinoma. However, mixed follicular and papillary, Hürthle cell and medullary carcinoma have also been described

(1). Primary papillary carcinoma has been reported most commonly to occur in ectopic thyroid tissue remnant in thyroglossal cyst, lingual thyroid and medially displaced thyroid tissue $(11,12)$. In our case, the FNAC report of the extrathyroid mass surprisingly revealed as papillary carcinoma of thyroid gland. The histopathological examination of the excised mass confirmed follicular variant of papillary carcinoma of thyroid gland and the tumors of the right lobe were reported as follicular adenoma with Hürthle cell changes.

Presence of papillary carcinoma in an extra-thyroid mass raises the possibility of an occult primary in thyroid gland. Few researchers mentioned carcinoma 
anywhere in the neck as metastatic and the primary lesion ought to be present in the thyroid gland (13). The differentiation between carcinoma arising from ectopic tissue and a metastatic carcinoma is difficult. Few factors may help indirectly in diagnosis, as separate blood supply of the ectopic tissue, no other history of malignancy, normal or absent orthotopic thyroid without history of surgery etc (5). Hebbar et al. suggested if any thyroglossal specimen demonstrates only papillary carcinoma, the entire specimen should be carefully searched in histopathological examination for the presence of non-neoplastic thyroglossal duct remnants and/or ectopic normal thyroid follicles. Presence of such tissues indicates the lesion less likely to be metastasis and more appropriate to be primary carcinoma arising from ectopic thyroid tissue. Therefore, it can help in taking decision for appropriate surgical approach, as total thyroidectomy might not be necessary in association with excision of ectopic thyroid mass if normal thyroid tissue or thyroid duct remnants are found (11). Ectopic thyroid papillary carcinomas are well differentiated and proper surgical treatment followed by radioiodine ablation can offer excellent prognosis (14).

In our cases, on histopathological examination, one of the section shows presence of normal thyroid follicles, which (normal thyroid tissue) was also evidenced in radioisotope thyroid scan accumulating irregular tracer. The malignant lesion was limited with an intact capsule. At the same time, no primary lesion was found in the normally placed right thyroid lobe. The surgeons performed a total thyroidectomy with excision of the extra-thyroid mass and sent her again to our institute for radioiodine ablation. We commended her ablation therapy with $100 \mathrm{mCi}$ of 131I on 43rd post-operative days and started levothyroxin replacement to maintain her thyroid status and to suppress the TSH level in order to prevent recurrence.

\section{CONCLUSION}

Ectopic thyroid carcinoma is a very rare condition. It is also difficult to differentiate carcinoma arising from ectopic thyroid tissue and a metastatic one. But, even in presence of a normal thyroid gland, an ectopic thyroid carcinoma should also be kept in mind as a differential diagnosis of a pathological mass in front of the neck. Metastasis from ectopic thyroid carcinoma should also be considered.

\section{REFERENCES}

1. Noussios G, Anagnostis P, Goulis DG, Lappas D, Natsis K. Ectopic thyroid tissue: anatomical, clinical and surgical implications of a rare entity. European Journal of Endocrinology 2011; 165: 375-82

2. Lianos G, Bali C, Anastasiadi Z, Lianou E, Papathanasiou V, Messinis T. Ectopic thyroid carcinoma. Case report. G Chir 2013; 34(4): 114-16

3. Klubo-Gwiezdzinska J, Manes RP, Chia SH, Burman KD, Stathatos NA, Deeb ZE er al. Ectopic cervical thyroid carcinoma-Review of the literature with illustrative case series. J Clin Endocrinol Metab 2011; 96(6): 2684-91

4. Yamamoto T, Tatemoto Y, Hibi Y, Ohno A, Osaki T. Thyroid carcinomas found incidentally in the cervical lymphnodes: do they arise from heterotopic thyroid tissue? Oral Maxillofac Surg 2008; 66: 2566-76

5. Shah BC, Ravichand CS, Juluri S, Agarwal A, Pramesh CS, Mistry RC. Ectopic thyroid cancer. Annals of thoracic and cardiovascular surgery 2007; 13: 122-24

6. Tucci G, Rulli F. Follicular carcinoma in ectopic thyroid gland. A case report. Il Goirnale di Chirurgia 1999; 20: 97-99

7. Mishriki YY, Lane BP, Lozowsky MS, Epsrein H. Hürthle-cell tumor arising in the mediastinal ectopic thyroid and diagnosed by fine needle asporation, light microscopic and ultrastructural features. Acta Cytologica 1983; 27: 188-92

8. Sood A, Kumar R. The ectopic thyroid gland and the role of nuclear medicine techniques in its diagnosis and management. Hell $\mathrm{J}$ Nucl Med 2008;11(3): 169-71

9. Batsakis JG, El-Naggar AK, Luna MA. Thyroid gland ectopias. Ann Otol Rhinol Laryngol 1996; 105: 996-1000

10. Hebbar KA, Shashidhar K, Deshmane VL, Kumar V, Arjunan R. Papillary carcinoma in median aberrant thyroid (ectopic) - case report. Journal of Clinical and Diagnostic Research 2014; 8(6): 1-3

11. Virginia A et al. Carcinoma arising in median ectopic thyroid (including thyroglossal duct tissue. Cancer 1974;34:1303-15

12. Fumarola A et al. Thyroid carcinoma arising in ectopic thyroid tissue within a neck branchial cyst. World Journal of Surgical Oncology 2006;4:24

13. Nuttall FQ. Cystic metastasis from papillary adenocarcinoma of the thyroid with comments concerning carcinoma associated with thyroglossal remnants. American Journal of Surgery 1965; 109: 500-5

14. O’Connell M, Grixti M, Harmer C. Thyroglossal duct carcinoma: presentation and management, including eight case reports. Clin Oncol(R Coll Radiol) 1998; 10:186-90 